\title{
CICLO DE CONVERSACIONES ANTROPOLOGÍAS DEL SUR: MILKA CASTRO LUCIC
}

\author{
CLAUDIO ESPINOZA* \\ LUIS CAMPOS ** \\ PAULA CONTRERAS ${ }^{* * *}$
}

\section{Resumen}

En esta tercera entrevista del ciclo de conversaciones Antropologías del Sur, cuyo fin es revisar y pensar formas no hegemónicas de la disciplina, se presenta la trayectoria académica e intelectual de Milka Castro Lucic (lquique, 1949), quien, desde sus inicios en la antropología, recorre un camino amplio para convertirse en experta en materias relacionadas con el derecho propio de los pueblos indígenas, la antropología jurídica, los derechos de agua y el estudio con poblaciones del norte grande y chico de Chile. La entrevista nos muestra sus inicios en el campo de la antropología que acompañan la institucionalización formal de la disciplina en la Universidad de Chile. En su relato aparecen hitos de gran importancia para la antropología chilena, como fueron el impacto en la naciente disciplina del golpe de estado de 1973, los intentos por mantener activa la carrera y las características de una escuela que debió acomodarse a un contexto dictatorial. También a lo largo de su vida se puede apreciar su participación directa en los primeros procesos de organización del Colegio de Antropólogos de Chile, de la organización de los primeros congresos de la disciplina en el país y también de otras instancias organizativas en el ámbito latinoamericano y mundial, como la Asocación Latinoamericana de Antropología (ALA) y la Red Latinoamericana de Antropología Jurídica (RELAJU). Sus investigaciones sobre el agua en el norte de Chile como su amplio trabajo en toda esa zona muestran a una destacada antropóloga chilena que ha conseguido trascender las fronteras nacionales contribuyendo tanto a la difusión como a la valorización de la antropología chilena en Latinoamérica y el mundo.

\footnotetext{
* Académico Escuela de Antropología, Universidad Academia de Humanismo Cristiano, Santiago, Chile. ** Académico Escuela de Antropología, Universidad Academia de Humanismo Cristiano, Santiago, Chile. *** Académica Escuela de Antropología, Universidad Academia de Humanismo Cristiano, Santiago, Chile.
} 
AdS: Milka quisiéramos partir conociendo un poco de tu vida personal. Que nos cuentes de tu infancia, del lugar donde naciste y creciste.

Nací en lquique, en el barrio El Morro, al lado del mar, donde mi abuelo croata Domingo Lucic Vlahovic, industrial de la sal, había instalado la refinería y, enfrente, la casa en que crecí, en la calle Isaza. Las pampas y el altiplano de Tarapacá que recorrió este abuelo comprando patentes de minas, salares y otras tierras, sería el camino que yo recorrería en mi trabajo con los pueblos indígenas desde 1979.

El Morro, era un barrio cosmopolita en donde residían algunas antiguas familias de origen peruano, inglés, alemán, chino, francés, italiano, croata y familias de pescadores. No había diferencias de nivel socioeconómico entre niños y adolescentes para compartir, jugando en las calles y en la playa; de hecho, el mar rodeaba nuestro barrio. Era muy especial, lleno de estímulos, de vida, calles de tierra, casonas que quedaron del tiempo del Perú, entremezcladas con otras más precarias, de madera. La particularidad de este barrio es la enorme cantidad de vivencias historias, personajes callejeros, formas de comercio ambulante de productos del mar (por ejemplo, pescados transportados en un yugo sobre los hombros de los pescadores), carretas tiradas por burros que traían productos para la venta, el tren salitrero que llegaba hasta la puerta de mi casa. El ingreso de autos al barrio era una novedad y ocasión de juego para nosotros. Y por cierto el juego con agua en el Carnaval era una instancia que nos unía $y$, por la noche fiestas en algunas casas. En fin, mucho que recordar.
El Morro era multicultural y socioeconómicamente diverso. Quien conoce parte de esas sabrosas formas de vida plenas de momentos de alegría y no exenta de dolor, en el territorio que fuera de los changos, reconocerá su identidad de "morrino/a", más que de iquiqueños. De este barrio, que conoció tiempos de gloria, salimos un número importante de representantes de las ciencias sociales. Sería largo enumerar a todos, -hay dos premios nacionales-, pero solo quisiera nombrar a Freddy Taberna, geógrafo, fusilado por orden de un Consejo de Guerra en el campo de prisioneros en Pisagua. Freddy había estudiado Geografía en el Instituto Pedagógico de la Universidad de Chile.

En la década de los sesenta toda mi familia migró a Santiago, donde continúe mis estudios en colegios católicos.

AdS: ¿Y cómo llegaste a la antropología, qué elementos gatillaron tu interés por estudiar antropología y cuáles eran tus expectativas respecto de la disciplina antropológica?

Bueno, el ingreso a la Universidad lo realicé el año 1971 cuando mis tres pequeños hijos entraron al colegio. En esa época me había sumado a la campaña de Salvador Allende, con una serie de actividades previas y posteriores a las elecciones que le llevaron a la presidencia, pero solo desde el barrio, en la comuna de Providencia, desde la organización vecinal. Fue en este contexto cuando conocí a la escritora Teresa Hamel. Ella, sin saberlo, marcaría los derroteros de mi vida. Un día mientras viajaba en su auto para realizar trabajo voluntario en la población Lo Hermida, le comenté que había tomado la decisión de ingresar a la Universidad, 
a lo que ella me comentó con convicción: a este país le faltan antropólogos. Me instaló la inquietud y curiosidad, pues no sabía que podría hacer una antropóloga en el contexto político que vivíamos, además que la antropología no era conocida. Pero lo cierto es que pronto me di cuenta que tenía mucha importancia el rol de las ciencias sociales, en general, en el programa de gobierno de Allende. Los tiempos que vivíamos eran muy estimulantes, se avizoraba un atractivo y enorme campo de acción en el marco del programa del gobierno de la revolución democrática, instalado en un complejo escenario internacional de confrontaciones entre capitalismo y socialismo. Más tarde vería cómo este antagonismo decantaba en la universidad donde se había abierto un rico desarrollo intelectual, generando una efervescencia ideológica, que estimulaba al estudiantado a inclinarse o decidirse por una posición.

\section{AdS: ¿Cómo era el departamento de antro- pología de la Universidad de Chile en el momento en que entras a estudiar?}

Me parece importante señalar que el Departamento de Antropología nace en el contexto de la Reforma universitaria del año 1968, resultado de muchos años de lucha de los estudiantes que se remonta a la segunda década del siglo $X X$. Pero es importante detenerme en los años 1967 y 1968, cuando la efervescencia política era un rasgo de todas las universidades del país, con movilizaciones estudiantiles, huelgas, toma de edificios, junto a asambleas donde luego de intensos debates se culmina con la gran reforma universitaria el año 1968. Se había luchado, entre otras cosas, por la democratización y por un rol de compromiso social de la institución. Existía, sin embargo, una división política, que se manifestaba en un espectro de detractores y defensores del gobierno de Eduardo Frei Ruiz Tagle, polarización que continuaría en el gobierno de Salvador Allende entre los años 1970 y 1973.

¿Por qué digo que nace en el marco de esta Reforma? El Departamento de Antropología, también fue producto de una larga historia de trabajos especialmente en el área de arqueología. La estructura del Departamento de Antropología Social y Arqueología de la Universidad de Chile, creado el año 1970, tuvo sus raíces en el Centro de Estudios Antropológicos creado en 1954 bajo la dirección del antropólogo norteamericano Richard Schaedel. Un número importante de profesores del Departamento, el año 1971, venían de este Centro; ellos eran Carlos Munizaga, Alberto Medina, Jorge Kaltwasser, Juan Munizaga, Bernardo Berdichewsky, Ximena Bunster, entre otros.

El Centro concebía la antropología como una ciencia social general que contenía la antropología física y la antropología sociocultural, la que a su vez comprendía la arqueología, etnografía, etnología, folclor, y etnolingüística. Fue este abanico de especialidades lo que atrajo, por esos años, el interés de un amplio espectro de profesionales de la arquitectura, medicina, botánica, educación, cultivando así la interdisciplinariedad. No obstante, fue la arqueología la que tuvo un desarrollo más vigoroso, logrando así que el año 1969, en el marco de la reforma universitaria, se creara en la Facultad de Filosofía y Educación, la Licenciatura en Filosofía con mención en Prehistoria y Arqueología. El desarrollo de estas actividades, por un lado, y la atracción de un número importante de estudiantes, por otro, fueron antecedentes suficientes para que la 
rectoría de la universidad aprobara la creación del Departamento de Ciencias Antropológicas y Arqueológicas, con la Licenciatura en Antropología en diciembre del 1970, y se decreta que el personal del Centro de Estudios Antropológicos debía trasladarse con sus funciones al nuevo Departamento. El flamante Departamento, que se abre el año 1971, contemplaba tres especialidades, Antropología Social, Antropología Física y Arqueología. En la elección de director se presentaron Bernardo Berdichewski y Mario Orellana, ganando este último en un reñido resultado.

Los cursos, que se impartían en el centro y otros en el Departamento de Historia, habían atraído un alto número de alumnos que, en algunos casos, se incorporaron para terminar sus estudios en el nuevo departamento de antropología. Esta trayectoria explicaría el hecho que en el primer año la carrera de antropología tuvo la particularidad de reunir una diversidad de estudiantes. Había quienes venían de otras carreras y otros más jóvenes que habían terminado recientemente el ciclo escolar, incluso hubo quienes venían de otros países. Fue un inicio fascinante por aquella diversidad. El plan de estudio era flexible, consideraba la libertad de cátedra, cátedras paralelas, podíamos escoger cursos impartidos por destacados maestros de otros departamentos o del Instituto Pedagógico, y con diferentes marcos teóricos. Me refiero a los dos grandes enfoques teóricos en ese tiempo: funcionalismo y materialismo histórico. Pero solo fueron dos años, luego con el golpe y la contra reforma todo cambiaría.

\section{AdS: ¿Qué cursos y qué enfoques te marcaron?}

Mirando hacia atrás emergen en mi memoria dos profesores, diferentes, que marcaron mi caminar por la carrera. Patricio León, admirable teórico y metodólogo, era el único profesor que se había titulado de antropólogo, graduado en la Universidad de Concepción, donde fue ayudante del profesor argentino Edgardo Garbulsky, y trabajaba también en el Instituto de Capacitación e Investigación en Reforma Agraria (ICIRA).

Su curso Introducción a la Metodología de las Ciencias Sociales en el primer semestre de la carrera, contemplaba los enfoques teóricos del materialismo histórico y el método dialéctico, el funcionalismo y el estructural funcionalismo. Digo que me impactó, porque en sus clases nos enseñaba sobre la importancia del método para llevar a la práctica un marco teórico, no me parecía un ejercicio fácil. De hecho, sus exámenes constituían un gran desafío al intelecto. Este afán de articular teoría y método, separando lo que consideraba las técnicas de campo, fueron al menos para mí un tremendo aporte. Hacía este ejercicio con todas las corrientes teóricas, pero fue la explicación y aplicación del método materialista dialéctico, lo que más llamó mi atención. Lamentablemente nunca más volvimos a tener clases sobre esas materias.

En sus clases nos estimulaba a tener valores como profesionales y analizar desde la teoría los diversos problemas que debe enfrentar un país. Recuerdo que nos espoleaba con sus enseñanzas, decía que un estudiante debía leer 100 páginas diarias. Era estricto, genial, gran profesor. Desafortunadamente, con el golpe de Estado, fue uno de los profesores marxistas que debió salir del país.

Lo cierto, es que el ingreso a una carrera de ciencias sociales exigía estudiar. Fuera del aula eran muy frecuentes las acaloradas discusiones políticas entre el estudiantado, a esas alturas, polarizado políticamente. Ello estimu- 
laba a tener un muy buen manejo de lo teórico, de las ideologías.

Un enfoque diferente, compartían los demás profesores de antropología social. Como señalaba, provenían de otras carreras: derecho, licenciaturas en filosofía con mención en historia, y licenciaturas en musicología y folclor. Hubo quienes se incorporaron como estudiantes especialmente en la carrera de arqueología, y otros que con posterioridad complementaron sus estudios con posgrados en antropología y arqueología. El núcleo duro de la carrera compartía una visión funcionalista y/o estructural funcionalista.

Una distinción especial merece el profesor Carlos Munizaga, sencillo, amable, maestro, de notable capacidad intelectual y tremendo entusiasmo por diversas materias como la arquitectura, botánica, arqueología, psiquiatría, literatura, educación, migración, realidades urbanas. Don Carlos, como le llamábamos, sin dudas, constituyó el principal pilar del departamento desde el inicio de la carrera. Con su partida dejó un gran vacío. No hubo nadie de su estatura académica que pudiéramos reconocer como un maestro. Es el sentir de muchos antropólogos y antropólogas de Chile que nos formamos con él. Tuve el honor de ser su ayudante en el curso Antropología Urbana y participar en sus investigaciones en los botaderos de basura; fue una experiencia única por todo lo que se puede imaginar lo que ello significa. Era un desafío para una futura antropóloga.

\section{AdS: ¿Qué otros hechos te marcaron de esa primera experiencia con la antropología?}

Bueno, un hecho que nos marcó despiadadamente fue el golpe militar. Cuando regresa- mos a clases, después del 11 de septiembre, no éramos los mismos, no estábamos todos... nos mirábamos con desconfianza y el miedo se instaló por mucho tiempo. Decían que había listas con nuestros nombres, cualquiera podía ser "soplón" y, de hecho, los hubo. Pero lentamente fueron apareciendo entre nosotros señales de identificación de cierta confianza, hasta que logramos reagruparnos construyendo espacios más seguros para compartir.

No solo se nos anularon los cursos que habíamos tomado con profesores y profesoras marxistas, se nos destruyó la hermosa biblioteca que estaba en la esquina de Grecia con Los Presidentes donde hoy está la Facultad de Filosofía y Humanidades. Los libros fueron retirados, tuvieron oscuros destinos, algunos decían que estaban a la venta en San Diego, otros no se sabía. Algo de lo permitido quedó en una pequeña sala que fue nuestra biblioteca en el departamento de antropología. Entendimos que había que adaptarse, aplicar en nuestros estudios solamente la teoría funcionalista. El paisaje ofrecía diversas opciones: antropología simbólica, ecología cultural, antropología social británica, teoría de sistemas, estructuralismo. Pasaron algunos años, hasta que tímidamente comenzaran a aparecer autores desde un marxismo estructural como Maurice Godelier, Terray, Sahlins, Friedman, entre otros. Pero nunca la comunidad científica volvió a ser lo misma. La estructura vertical que instaló la dictadura marcó una nueva forma de hacer universidad. El control del poder, la verticalidad en las relaciones, la formación de grupos que podían decidir arbitrariamente sobre el destino de las carreras y del profesorado, también se habían instalado en el nuevo escenario universitario. 
AdS: ¿Qué otros cambios ocurrieron en la formación antropológica a partir del golpe de Estado? ¿De qué modo se vieron afectadas las clases y cursos de la carrera?

La carrera de antropología no se cerró, tal vez porque hubo gran parte del profesorado que definitivamente no era de izquierda, sino de derecha y de orientación conservadora y lo mismo ocurría respecto del estudiantado. El regreso fue muy traumático, cambió todo. Desde el cambio en la vestimenta, especialmente en los hombres, regresaron con cierta formalidad, sin barba, con el pelo corto y con vestón. También se instaló un cambio en las relaciones. Por largo tiempo se mantuvo la desconfianza hacia el otro, cualquiera podía ser soplón o "sapo", por tanto, el diálogo debía ser estrictamente formal. Se sabía de cierto personal de servicio y alumnos que eran informantes de los militares.

Nos fuimos dando cuenta que algunos estudiantes y profesores chilenos y extranjeros no regresaron porque se habían ido al exilio o retornado a sus países. Las reglas habían cambiado, como dije, se nos anularon cursos que habían sido impartidos por profesores marxistas, por lo que tuvimos que repetirlos con el profesorado autorizado. En la dirección del departamento quedó el arqueólogo Mario Orellana, y en el decanato Carlos Munizaga, quien sería el principal diseñador de la malla de la carrera.

Por cierto, que se eliminaron todos los textos de marxismo, estaba prohibida su lectura; de hecho, la mayoría había quemado en sus casas toda la literatura que pudiera comprometerlo. El profesorado, como he señalado, no tenía formación de pregrado en antropología, provenían de otras disciplinas. Lo que recuerdo de aquellos años era una pregunta muy recurrente: ¿para qué sirve la antropología? Teníamos una nutrida malla, pero tan diversa que no era fácil encontrar la conexión entre los cursos que debíamos tomar. Esa pregunta se repetiría por varios años. Reflexionando, desde esta entrevista, ello era porque se produjo una desconexión con el desarrollo de la sociedad y porque no veíamos en nuestros profesores, no antropólogos, sus campos de acción o trabajo. Este fue un camino que iniciamos los primeros antropólogos, en el campo de la educación y del desarrollo rural preferentemente. Las organizaciones no gubernamentales fueron un espacio de acogida para quienes egresaban. En general, pienso que estudiábamos para terminar como investigadores, y no para hacer ciencia aplicada, proyecto que era fomentado antes de la dictadura. Cada egresado tomaba su camino y debía ir aprendiendo de la propia experiencia.

\section{AdS: Si pudieras profundizar más en el contexto nacional intelectual existente antes del golpe de Estado.}

Mientras estudiaba, entre los años 1971 y 1973, los cursos tenían escasa relación con una serie de centros donde trabajaban destacados intelectuales europeos, latinoamericanos y chilenos, aunque sí consultábamos sus publicaciones en los cursos superiores. Destaco los siguientes: CEPAL (Comisión Económica para América Latina y el Caribe), que se había instalado en Santiago a mediados del siglo XX, donde Raúl Prebisch desarrolló la teoría de relaciones centro y periferia; de sus lecturas se podía analizar las causas del subdesarrollo. ILPES (Instituto Latinoamericano y del Caribe de Planificación Económica y Social), parte de CEPAL, pero con orientación en planificación y gestión pública, creado en los años sesenta; 
atrajo a destacados intelectuales, recuerdo las lecturas de Osvaldo Sunkel, con el libro "El Subdesarrollo Latinoamericano y la Teoría del Desarrollo", y de Fernando Henrique Cardoso y Enzo Faletto con la conocida obra "Dependencia y Desarrollo en América Latina. Ensayo de interpretación sociológica". FLACSO (Facultad Latinoamericana de Ciencias Sociales), donde Carlos Munizaga cursó un postgrado en Sociología en los años 60; acá estuvo el sociólogo noruego Johan Galtung. Recuerdo su libro "Teoría y métodos de la investigación social", que usamos en nuestra formación; Hugo Zemmelman, quien también fuera Director de la Escuela de Sociología de la Universidad de Chile, y realizara importantes contribuciones sobre el mundo rural y las migraciones. Peter Heinz, sociólogo suizo, leímos su libro "Un paradigma sociológico del desarrollo". Esta institución atravesó una difícil situación al verse involucrada en un proyecto que tenía como objetivo realizar un estudio comparativo entre varios países. Se invitó a participar a investigadores de la Universidad de Chile, entre ellos Ximena Bunster, antropóloga. Sin embargo, algunos investigadores extranjeros obtuvieron información sobre la verdad del proyecto Camelot. Este era financiado por el Departamento de Defensa de Estados Unidos para obtener información del potencial revolucionario en el país, lo que desató un gran escándalo en la academia.

Bueno, pero siguiendo con estos centros, en la Universidad de Chile, en la Facultad de Ciencias Económicas, estaba el Centro de Estudios Socio-Económicos (CESO), desde mediados de los sesenta, quienes editaban la revista Sociedad y Desarrollo. En este Centro estuvo Theotonio Dos Santos y Marta Harnecker discípula de Louis Althusser. Conocido fue su libro "Los conceptos elementales del materialismo histórico". Por último, de los que recuerdo, está CEREN (Centro de Estudios de la Realidad Nacional), dependiente de la Universidad Católica, siendo su primer Director Jacques Chonchol, quien sería Ministro de Agricultura del gobierno de Salvador Allende. También estuvo en la dirección Armand Mattelart, sociólogo belga. Entre sus publicaciones leímos "Los medios de comunicación de masas en un proceso revolucionario". CEREN editaba la revista "Cuadernos de la Realidad Nacional". Se había creado, además, en el gobierno de Eduardo Frei, el ICIRA (Instituto de Capacitación e Investigación en Reforma Agraria), dependiente de FAO y del gobierno. Recibió una selecta cantidad de intelectuales como Paulo Freire. Conocida es su obra "La Educación como práctica de libertad" y "Pedagogía del Oprimido". Otros profesionales chilenos que trabajaron para ICIRA fueron Rafael Barahona y Jorge Echeñique, a quienes leímos con posterioridad en nuestro interés por el tema rural.

\section{AdS: ¿Cómo fue estudiar antropología durante la Unidad Popular? ¿Hacían trabajo de campo?}

Durante el período que duró la Unidad Popular los terrenos fueron escasos. Recordemos, además, que desde la apertura de la carrera al golpe de Estado solo tuvimos dos años. Nuestro ciclo básico, de dos años tuvo cursos muy interesantes, pero solo uno o dos eran de la especialidad de antropología. Recuerdo que el primer año tuvimos que ir a terreno para realizar un ejercicio en que debíamos aplicar los contenidos de la materia de clases. Fue para un estudio del curso Geografía Humana, que impartía la profesora de Geografía Lily Nilsen. Este curso lo anuló la dictadura y el año 1973 lo tuvimos 
que hacer nuevamente, con el profesor Pedro Cunill. Recuerdo también la invitación del profesor Domingo Curaqueo quien impartía el curso de lengua mapuche, para asistir a un Nguillatun en una comunidad en el sur. Eso fue todo. Pero, en general, quienes sí iban a terreno eran estudiantes que venían colaborando en proyectos de arqueología y antropología física, con investigadores de larga trayectoria del Centro de Estudios Antropológicos. Pero no ocurría lo mismo con la antropología. Nosotros no teníamos ese respaldo de un profesorado graduado en antropología con una trayectoria de investigaciones en antropología social.

Mirando hacia atrás veo que la antropología social en el departamento comenzó, en verdad, con nosotros, los primeros estudiantes que egresamos.

En cuanto a la orientación del trabajo en terreno, creo que a muchos nos motivaba el hecho de vivir en un tiempo histórico en el que la concepción de una ciencia para la sociedad estaba contenida en los proyectos de los discursos políticos, algo que venía desde el gobierno de Eduardo Frei Montalva, con la llamada revolución en libertad y la Reforma Agraria. El compromiso de las ciencias sociales con la sociedad era reforzado por algunos profesores y lecturas. Recuerdo que tuvimos oportunidad de leer autores sobre ciencia aplicada. En uno de los ramos llamó mucho mi atención el libro "La Ciencia", de Kedroov y Spirkin, quienes planteaban una ciencia que debía permitir conocer y explicar la realidad para transformarla, con el objetivo de beneficiar a la sociedad. Creo que la mayoría pensaba en una antropología aplicada, porque, como ya señalé, los tiempos eran propicios y motivantes. Hubo un importante intelectual de prestigio latinoamericano, que sí tenía gran experiencia etnográfica y trabajaba con sentido de compromiso social, Alejandro Lipschutz, médico, devenido en un prestigioso antropólogo, considerado como precursor de la antropología social. De hecho, realizó importantes aportes etnográficos en la zona mapuche y fueguina, había participado en la creación del Instituto Indigenista Interamericano a mediados del siglo XX, y tenía un vasto conocimiento sobre el indigenismo de aquellos años y fue reconocido internacionalmente por ello. En nuestra época de estudiantes, durante la Unidad Popular fue asesor de Salvador Allende en el tema indígena en general y en la Reforma Agraria en la zona mapuche. Sin embargo, no fue un antropólogo que tuviéramos que leer, tal vez porque era un científico de izquierda. $Y$ cuando entramos al ciclo especializado, durante la dictadura, estuvo prohibida su lectura. Solo quedaba la opción personal, que en los primeros años debíamos evitar, por temor a lo que ocurría en nuestro entorno.

\section{AdS: ¿Cuál era la relación entre estudiar una carrera universitaria y el activismo político?}

A ver, si estamos de acuerdo que el activismo político era la participación de los estudiantes en movimientos o partidos comprometidos con los cambios que se esperaba transformaran la sociedad, sí había activismo político. Recuerdo que existía una vinculación muy estrecha. La politización del alumnado y profesores se vía como un proceso creciente, esto iba de la mano con un escenario político del país que incrementaba la polarización. Fue un proceso progresivo.

El hecho que la antropología hubiera nacido en el campus oriente de la Universidad de Chile, más conocido como el Pedagógico, nos hacía 
parte del ambiente académico y político que se vivía, puesto que compartíamos espacios y cátedras con estudiantes del Instituto Pedagógico, de Sociología, Filosofía y otras de la Facultad de Filosofía y Humanidades. En mi opinión ese ambiente estimulaba el estudio y la participación política. Los debates eran de muy buen nivel, especialmente entre sus dirigentes. El "Pedagógico" era sin dudas un potente centro de debate político e ideológico, donde predominaban las juventudes comunistas, socialistas, el Movimiento de Izquierda Revolucionario MIR, y algunas corrientes anarquistas. EI MIR, creado en Concepción alrededor de 1964, el Frente de Estudiantes Revolucionarios (FER), entre otras. Recuerdo que algunos compañeros de antropología eran dirigentes con una vocación admirable. Por ello, me sorprendió muchísimo cuando hubo quienes, después del golpe, dejaron su militancia para arrimarse al sector conservador, opción política que sería predominante en nuestro departamento. Antes de la dictadura la derecha estaba instalada principalmente en la Universidad Católica, representada por el partido Nacional, y dos movimientos nacionalistas más, el Movimiento Gremial de la Universidad Católica creado por Jaime Guzmán en el 1967 que controlaba la organización estudiantil, y el Frente Nacionalista Patria y Libertad, creado a comienzos de 1971. Estos dos últimos tuvieron altísima participación estudiantil, pero no eran visibles en el Pedagógico. En cuando al partido Demócrata Cristiano lo recuerdo en una actitud de abierta confrontación con la izquierda, hubo incluso violentos enfrentamientos en otras Facultades. La politización y polarización era casi inevitable, aunque hubo un sector que no manifestaba abiertamente su posición política, tal vez por esa efervescencia política estudiantil que vivíamos. De hecho, hubo estudiantes que habían comenzado a participar en los "Cordo- nes Industriales", formas de organización de los trabajadores, para boicotear el paro de las empresas por sus dueños, haciéndolas producir sin ellos.

AdS: Volviendo a la universidad y mirando en retrospectiva ¿Cuál era la concepción de la antropología y del quehacer antropológico que tenía el departamento de antropología de la Universidad de Chile? ¿Cuál era, por decirlo de algún modo, su proyecto?

Recordando cómo era la concepción de la antropología y del quehacer antropológico en la década de los setenta, y específicamente en torno a antes y después del golpe, volvería a lo que ya he señalado. El Departamento de Antropología de la Universidad de Chile inicia su historia en 1971, pienso que pudo haber sido un excelente departamento, pero se le cortaron las alas a los dos años de nacer, y después del golpe militar se le trazó una ruta que ha seguido tal vez hasta tiempos recientes. Lo digo así, porque en mi experiencia, cuando ingresé a estudiar antropología, cada día de los pocos que fueron finalmente, era una constante expectación por descubrir el clima intelectual y político que se vivía. Conocer y asistir a las aulas de los grandes maestros admirados por el estudiantado hacía propicio que también muchos estudiantes tuvieran una actitud muy profesional, lo que era posible apreciar en las conversaciones y discusiones políticas en patios, cafés y asambleas, y también tremendamente comprometidos con el desarrollo de la sociedad. Había que estudiar, estábamos motivados, el estudio tenía sentido. Y sabíamos que nuestro vecino, el Pedagógico, era una potente y prestigiosa fuente de conocimientos, de él habían salidos notables premios nacionales, 
decanos, rectores; y aunque nosotros éramos parte marginal, nueva, había redes de relaciones políticas con nuestros líderes de antropología. Todo este ambiente rodeado por una motivación hacia el arte, la poesía y la música. Fue así como después de la dictadura nos unían canciones que entonábamos con cierta prudencia, por su comprometida letra. No faltaba una guitarra para entonar por ejemplo "Que la tortilla se vuelva", "Qué dirá el santo padre", y tantas otras de la guerra civil española, de Victor Jara, Violeta Parra o corridos de la revolución mexicana o canciones del legado indígena, y tantas más... todo ello nos imprimía cierta identidad de incierto destino.

Entonces, lo que quiero destacar es que pensábamos en un proyecto de carrera que tuviera el sentido que estábamos viviendo en nuestra formación. La fuerza y compromiso de los estudiantes y profesores se había nutrido en la historia. El pedagógico había vivido intensamente el período de la reforma universitaria de los sesenta, los y las jóvenes habían compartido también la revolución de mayo del 68' en Francia, cuando los estudiantes iniciaron una gran revolución intelectual y cultural contra instituciones establecidas, así como contra la guerra de Vietnam y el sistema económico. Intelectuales como Louis Althusser, Herbert Marcuse y JeanPaul Sartre, permearon las ciencias sociales en el contexto latinoamericano. En fin, éramos parte de luchas que tuvieron lugar por los estudiantes dentro y fuera de Chile. Por cierto, estas posturas dividían al estudiantado. $Y$ por otra parte, el departamento de antropología y arqueología, tenía su propia historia: la de un grupo consolidado de profesionales de notable prestigio académico, básicamente del área de la arqueología y antropología física, que venía estudiando, investigando y publicando desde inicios del siglo XX, conjuntamente a connotados investigadores extranjeros. Yo podría afirmar que, al menos nosotros, los estudiantes, no percibimos que hubiera un proyecto para el desarrollo de carrera de antropología social; pero sí estaba en nuestras expectativas, producto del escenario que he señalado, tanto desde el punto de vista académico como político.

\section{AdS: ¿Y cómo fueron tus primeros años de graduada y ya como profesional de la antro- pología?}

Poco antes de graduarme, por los años 74-75, algunos profesores generaron líneas de investigación con la participación de estudiantes. Fue de mi interés por esos años el grupo de antropología urbana en el que participaba Sergio Martinic, María Paz Arrigorriaga y otros que no recuerdo porque no continuaron, todo esto al alero del profesor Carlos Munizaga, de quien fui ayudante. Mi interés estaba en esos años en las vidas marginales, la pobreza urbana. Leíamos textos de Oscar Lewis sobre antropología y pobreza, Charles Valentine, cultura de la pobreza y otros, y por cierto surgían los debates acerca de si la pobreza podía ser considerada como una cultura. Este tema se cruzaba con otras teorías sobre la marginalidad que estaban de moda y que también suscitaban debates, cuestionando el mismo concepto.

Recuerdo las publicaciones de DESAL (Desarrollo Social para América Latina) encabezado por Roger Vekemans, sacerdote jesuita; las teorías del sociólogo Gino Germani. Otro concepto de la época era desarrollo y subdesarrollo y nuevamente, el cuestionamiento y las explicaciones teóricas sobre ellos; CEPAL era otro centro para consultar bibliografía donde 
leíamos autores como André Gunder Frank, Osvaldo Sunkel y tanto otros. Fui centrando mi interés en la pobreza y la marginalidad. Con Sergio y María Paz iniciamos un trabajo de campo en los basurales de Santiago. Qué más pobre y marginal que un basural y su gente. Fuimos a un botadero que estaba camino a Tiltil y otro que estaba en lo que ahora es la rotonda Quilín. Fue la experiencia más difícil que había tenido, por las condiciones de ese mundo. Ingresar a un botadero, ver como las personas vivían en y comían de la basura que dejaban los camiones diariamente, fue una experiencia impactante, pero enriquecedora para los principios que guiaban mi vida profesional, inolvidable. Fuimos un par de veces, aún cuando tuviéramos que caminar sobre la podredumbre del basural, con nubes de moscas que se elevaban cuando pasábamos y luego volvían a posarse en la basura. Investigamos la organización para el trabajo dentro del botadero. Observar atónitos como se producía una algarabía cuando llegaba un camión, porque luego ordenadamente se repartían la basura que trasportaban en canastos hacia los lugares asignados de cada uno, para escarbar y seleccionar. Un día llegó un camión con carne podrida, del matadero, con la orden de enterrarla. Olía muy fétido. Para los recolectores fue una fiesta: llegó la carne gritaban... pero ahí estaba funcionado el modelo económico, esa basura que se separaba por productos, regresaba al mercado, las latas a la minería, nos explicaban. A mí me llamó mucho la atención la adaptación física a la basura, cómo no morían tomando agua contaminada llena de moscas, todo lo comible se aprovechaba; se dormía en la basura, construían rucos. Nosotros nos dimos cuenta que el aire estaba contaminado por la podredumbre y salía del suelo olor a gas. Las personas ahí no existían para la sociedad; el alcohol y la violen- cia estaban presentes. En ambos basurales la jefatura y el orden lo imponía una mujer. Ocurrió que María Paz comentó sobre este estudio a unos amigos de la Facultad de Medicina y se interesaron por escucharnos. Fuimos a dar una charla. Pero acá viene lo interesante para mí, porque ellos tenían un proyecto en el altiplano sobre adaptación biológica a la altura y necesitaban algún antropólogo. Nos invitaron a uno de sus viajes y fuimos. La atracción, el interés por conocer ese desolado mundo del que tanto se escribía, fue sin retorno. Y desde 1979 hasta hoy mantengo un profundo vínculo con el norte grande, ese norte que desde lquique me expulsó a Santiago y que por la basura regresé a sus montañas.

El grupo de biología celular y genética de la Universidad de Chile tenía un proyecto financiado por UNESCO, institución que luego financiaría el estudio antropológico, y el año 1981 me envían una invitación para exponer, en inglés, mi trabajo en un Congreso Internacional de Ecología. Expuse en un pódium de UNESCO, en París, frente a un público de todos los continentes. El salón era espectacular, las banderas de cada país frente a sus representantes, me atemorizaba, pero todo salió bien. Y claro, empiezan los contactos. Fue tan inesperado, como increíble ese viaje, primera vez que salía a Europa, fui sola y mi espíritu aventurero me hizo no perder la oportunidad de conocer otros países, España, Italia, Suiza, Inglaterra, Suecia. Bueno, de ahí para adelante, recibí muchas invitaciones que me llevaron a China, Australia, Ghana, y varios otros países. Pero como antropóloga tenía contradicciones. Los lazos que establecía con las personas del mundo andino eran de tal intimidad y confianza que me cuestionaba mucho escribir sobre lo que amistosamente compar- 
tían conmigo. Solo me sentía cómoda con los relatos, creo que hasta ahora es así. Conocía la profundidad de la vida andina, compartiendo trabajo con ellos, ceremonias con todo lo que ello conlleva. En esos años para subir al altiplano había que ir en camiones o solicitar a alguna institución que te llevara en sus camionetas. El frío, temperaturas con menos de 20 grados, la hipoxia y los males que ella genera, no impidieron que volviera todos los años, hasta hoy.

Sentía que el antropólogo no solo debe buscar información para sus publicaciones, pero no sabía cómo hacer una ciencia aplicada. No había maestros. La pauta de terreno de mi primer trabajo la extraje de una publicación del destacado antropólogo quechua, que después sería mi amigo, Jorge Flores Ochoa, sobre las estrategias de subsistencia en el altiplano, especialmente el pastoreo, a 4.300 metros sobre el nivel del mar. Luego, por fin tuve una oportunidad indirecta de poder retribuir. Fue cuando Pinochet promulgó el Código de Aguas, que la privatiza y me doy cuenta que comienza la lucha por el agua. Ya en democracia, el director de la Dirección General de Aguas me llama a una reunión, le habían dado mi nombre, y me solicitó que hiciera un estudio sobre las vegas de altura, preocupado por los conflictos por el agua que se habían originado en el norte del país. Conformé un equipo interdisciplinario, recorrimos cada fuente de agua de toda la I y II Región, y demostramos que había una demanda por derechos de agua de tal magnitud que si se otorgaban derechos se secarían los humedales, eso fue en 1991. La contundente información que entregamos, con planos, fue presentada al Congreso y se introdujo un cambio en uno de los artículos para proteger esos humedales. Pocas personas saben de esto y tampoco se dio mayor importancia en mi propia Facultad de Ciencias Sociales. Después de ese estudio vinieron otros, pero yo desvié el camino hacia los derechos de los pueblos. Supo de mi trabajo un grupo de abogados y antropólogos preferentemente holandeses y alemanes, y me invitaron a Ghana, África. En esa reunión, conversamos sobre lo que ellos hacían como Sub Comisión de Derecho Consuetudinario y Pluralismo Jurídico. Todo era nuevo para mí, pero me escucharon sobre la emergencia del movimiento indígena en Latinoamérica, se interesaron mucho, y yo también, aún sin saber mucho de lo que hacían. Con su apoyo organicé un grupo similar en un Congreso de Americanistas en Quito, junto a María Teresa Sierra, el año 1997, y lanzamos la primera reunión de la Red Latinoamericana de Antropología Jurídica (RELAJU), que sigue reuniéndose hasta el día de hoy cada dos años: abogados, antropólogos, sociólogos y otras disciplinas, nos reunimos religiosamente. Son congresos de muy buen nivel. Durante un congreso en Colombia se organizó en homenaje a quien suscribe junto a un abogado holandés André Hoekema, como los gestores de RELAJU.

En fin, desde ese encuentro de Ghana, con una fuerte base de conocimientos empíricos, continúo trabajando por los derechos de los pueblos indígenas. $Y$ eso es largo de contar. Pero en esa vuelta siempre me reencuentro con mi primer año de antropología y los maestros y maestras que ya no están y las enseñanzas de ser consecuente, en la medida en que cada uno lo sienta y pueda. 
AdS: Milka volviendo un poco a los años posteriores al egreso, en plena dictadura ¿Cómo recuerdas la labor de la antropología en esa época y del papel jugado por la Universidad de Chile en ese proceso? ¿Cómo fue la lucha?

¿Cómo fue la lucha? Fue una lucha primero por salvarnos. No se pueden imaginar cuán aterrados estábamos; el golpe fue fuerte, igolpeó! Sabíamos que seguían desapareciendo personas, el miedo duró muchos años. Recuerdo que en mi primer camino hacia la Universidad pude ver en la calle una persona tirada con un balazo en la espalda, era en la mañana, cualquiera podía verlo; mucho se comentaba de cadáveres en calles, poblaciones, en el río Mapocho. Pero si soy honesta les digo que me costaba creer, me negaba interiormente a creer que fuera cierta tanta atrocidad, crueldad, traición, el horror de lo que estuviera ocurriendo, se nos había dado vuelta el mundo y estábamos bajo un poder implacable. Cuando regresamos, nos mirábamos, como ya lo he mencionado, con inmensa desconfianza. Como se ha dicho por ahí, el miedo fue el gran triunfo de la dictadura. Solo en los profesores y estudiantes de derecha se observaba serenidad y en algunos hasta cierta postura triunfalista y amenazante.

En una ocasión un compañero a modo de broma me señaló delante de un grupo de estudiantes como una persona de izquierda, quedé aterrorizada, pero fue un "estigma" que me acompañaría por mucho tiempo. Se hablaba de "listas negras", mecanismo de control de los servicios de inteligencia sobre académicos, estudiantes y funcionarios. $Y$ cómo no tener miedo, recuerdo que cuando nos informaron que el director del departamento, Mario Orellana quien en sus clases era en cierto modo valiente y bastante crítico a la intromisión militar en la Universidad- un día a finales del año 1975, había sido detenido y llevado a un centro de tortura, se decía que a Cuatro Álamos, pero no tengo certeza. Ese día fue tal el impacto que me causó, que perdí la voz, quedé afónica. Pensar que a cualquiera le podía pasar. También había sido detenido nuestro profesor de lingüística, Gilberto Sánchez, su delito era una pasantía en una universidad de Budapest. En el lugar de Mario Orellana, asumió como director, designado por la Junta Militar, el profesor de Folclor Manuel Dannemann.

Me encontraba impartiendo algunos cursos cuando comenzó a surgir la organización estudiantil, por el año 1981. Los compañeros, los estudiantes de los años setenta, eran profesionales que se encontraban trabajando en Universidades, Ong`s o Ministerios. En general, la pasividad del cuerpo docente del departamento contrastó con el inicio de la movilización estudiantil en la universidad y en la antropología, en particular.

A fines de los años setenta, bajo la figura de la Agrupación Cultural Universitaria (ACU), comenzó a gestarse la rearticulación. Los estudiantes de antropología realizaron reuniones y acordaron unirse a la organización y a las demandas de la escuela de Filosofía del Pedagógico y también de otras escuelas. Una decisión histórica fue el plegarse, en noviembre de 1980, a un gran paro estudiantil que duró tres semanas, con "toma" de la universidad y una huelga de hambre de sus dirigentes. $Y$ ello ocurrió aún cuando, en esos años, los intentos de organización estudiantil fueron castigados con persecuciones, detenciones, exilio y relegaciones a zonas aisladas del país. Al año siguiente, en 1981, hubo otro gatillante, ya que 
se promulgó la conocida Ley General de Universidades que separaba a la universidad de sus sedes y del Instituto Pedagógico, es decir la Universidad de Chile es desmembrada y perdía sus sedes en regiones a lo largo del país. La Facultad de Ciencias Sociales, creada en 1972, pasaría a conformar la Facultad de Filosofía, Humanidades y Educación, la que, en el afán de desarticular la organización estudiantil, fue trasladada a la sede La Reina, muy alejada, hacia la precordillera, donde funcionarían solo cuatro departamentos. Este escenario aumentaba las protestas de los estudiantes y en la sede de La Reina surgieron dos importantes líderes de la carrera de sociología y filosofía. En una histórica manifestación, los estudiantes decidieron marchar, recorriendo un extenso camino para reunirse a una masiva protesta en la biblioteca del ex Pedagógico, en Avenida Grecia, junto a otras facultades. En este lugar, fueron atacados por carabineros y bombas lacrimógenas, pero nada los detuvo. Salieron del lugar marchando hacia la Avenida Macul, donde la represión fue más fuerte.

Otro hito importante resultado de tantas tomas, marchas y barricadas, fue la culminación en las primeras protestas de mayo y junio de 1983, con trabajadores y estudiantes. A partir de este año el movimiento estudiantil se convirtió en un importante actor nacional. Fue así como al año siguiente, se refundó la Federación de Estudiantes de la Universidad de Chile, la FECH. El año 1987 se designó al primer rector civil, José Luis Federici, quien anunció un plan de racionalización. Esta medida despertó una serie de protestas de estudiantes, académicos y funcionarios. Se decía que impondrían reducción de personal, cierre de carreras, venta de bienes de la universidad, etc.. En respuesta hubo manifestaciones realmente masivas en las calles y facultades, y salimos, desde la casa central, a protestar en las calles liderados por el presidente de la Asociación de Funcionarios, el profesor Patricio Basso. Hubo profesores y alumnos detenidos hasta que, por fin, después de tres meses, Federici fue removido de su cargo. Todos estos episodios, con una alta y efectiva participación estudiantil, culminarían en el plebiscito del año siguiente, el plebiscito de 1988.

AdS: Por esos años, a mediados de los ochenta, surgió también el Colegio de Antropólogos. Tú fuiste protagonista en ese proceso ¿Qué nos puedes contar acerca de ello? Y ¿Cuáles eran tus expectativas sobre el funcionamiento del colegio?

En ese escenario de lucha contra la dictadura que amenazaba también a la universidad, en 1983 decantó la idea que se venía discutiendo sobre la creación de un Colegio de Antropólogos. Era una aspiración mayoritaria de profesionales que tenían una opción férrea de defender la profesión, especialmente durante la dictadura. Teníamos que generar espacio para ello. Hubo oposición, desacuerdos, básicamente de profesores del departamento de antropología de la Universidad de Chile. Se cuestionaban los estatutos por la alta participación de egresados y no titulados que podrían colegiarse. Por otro lado, se cuestionaba el doble carácter, por una parte gremial que se pensaba sería una especie de sindicato y la opción alternativa de crear un centro científico. Lo cierto es que a 10 años de creada la carrera habíamos pocos titulados, lo que no debía ser impedimento para iniciar un Colegio en un tiempo que era muy necesario. Había estudiantes detenidos, torturados y desapare- 
cidos. Tuvimos reuniones conjuntas que terminaron en la no aprobación de los estatutos, que habían sido elaborados y discutidos en detalle. Fue tan desgastador que en una última reunión que tuvo lugar en el Museo Precolombino, se manifestó abiertamente el conflicto. La resistencia a su creación, colmó a los participantes y una profesional expresó a nombre de quienes veníamos trabajando esta idea, el malestar y la desconfianza por las reiteradas manifestaciones de un sector para impedir que se creara un Colegio, puesto que la sociedad lo que más necesitaba eran espacios de encuentros y debate. Y se retiró. Detrás de ella hicieron abandono de la sala los demás profesionales y la sala quedó medio vacía. No sabemos qué ocurrió dentro, pero mientras discutíamos lo ocurrido en el patio del museo, salió un miembro de quienes presidían la asamblea para solicitar que regresáramos. Ese día nació el Colegio. Posteriormente, en una asamblea, se eligió el primer directorio, que tuvo como presidente a Mario Muñoz y como vicepresidenta a quien suscribe.

En cuanto a mis aspiraciones, lo que me interesaba de sobre manera era poder tener un espacio de encuentro académico para todos y todas los egresados y titulados del país, pues era necesario conocer lo que cada uno estaba haciendo, los temas que estaban investigando en dictadura, con todas las limitaciones que habían y crear o fortalecer nuestra identidad. Y terminar con la pregunta ¿para qué sirve la antropología? Por ello, cuando se creó una comisión para organizar el primer congreso, no dudé en aceptar el rol de secretaria ejecutiva. En la organización del congreso participaron antropólogos que estaban en proceso de titulación. El resultado fue un gran éxito, el reencuentro fue emocionante, y los resultados, las ponencias, fueron prontamente impresas. Cerramos el congreso con una fiesta inolvidable, todos bailaban, reían.

El temor que tendría la dictadura y sus aliados a nuestra organización quedó demostrado cuando en medio de la realización del congreso, llamaron por teléfono diciendo que habían puesto una bomba. Nos reunimos, analizamos qué hacer. Nos quedaba la alternativa de salir corriendo y con ello abortaba nuestro primer congreso, o quedarnos, sin pretender ser víctimas o "mártires", esperando que fuera solo una amenaza. Esperamos y así terminó el día y nada ocurrió.

AdS: ¿Y cómo fueron tus periodos como presidenta del Colegio de Antropólogos de Chile? ¿Qué nos cuentes de tus periodos como presidenta del Colegio de Antropólogos? ¿Cuáles eran las principales líneas trabajo? y ¿Cuáles crees que fueron los principales aportes de esa época y del Colegio de Antropólogos al desarrollo de la antropología chilena?

Mi compromiso con el Colegio comienza, como comenté, ante de su creación, un largo proceso para llegar a acuerdos con otro sector que presentaba oposiciones. Mi convicción y opción siempre fue el fortalecimiento del conocimiento científico. Los estatutos del colegio tienen varios otros objetivos, pero aquel fue mi guía. Cuando se crea el colegio fui elegida vicepresidenta el año 1984. En una de nuestras reuniones surgió la idea de organizar un congreso el año siguiente, 1985 y el directorio me solicitó que asumiera la organización. Estaba tan convencida que había que crear espacios de encuentro, después de la desarti- 
culación que nos causó el golpe de Estado, que acepté el desafío de inmediato. Digo el desafío, porque el colegio no tenía financiamiento para ello, ni tampoco teníamos la experticia para organizarlo, por lo que tuvimos que levantarlo artesanalmente, empezando por solicitar apoyo económico. Fue tan limitado y escaso el presupuesto que logramos reunir solicitando aportes a todas las instituciones que conocíamos, que fue una aventura lograr después el apoyo para una sede... el histórico y hermoso Café Torres. Nos movía el convencimiento de fortalecer la organización, la identidad y conocer en qué estaban trabajando $\mathrm{y} / \mathrm{o}$ investigando quienes iban egresando de la carrera. Los estatutos del congreso establecían, en el artículo 2, que había que estimular la investigación y organizar congresos y otras formas de encuentros que potenciaran la disciplina. Ese fue mi derrotero y hubo que trabajar y luchar muchísimo. El éxito que tuvo este primer congreso significó que hubiera acuerdo en su continuidad ya que en la asamblea final se acordó que el siguiente congreso sería en la ciudad de Temuco. Debía ser en 1988. Pero ocurrió que después de este encuentro correspondía elegir nuevo directorio. Yo no participé, aún siendo elegida para un cargo, por decisión personal, por no estar de acuerdo con algunos aspectos del proceso eleccionario. Mi tarea como Secretaria Ejecutiva del primer congreso terminó con la publicación de las Actas.

Pasaron los años, vino el gobierno democrático y se desarticuló el colegio y no se dio continuidad a los congresos. Observaba con cierta pesadumbre lo que ocurría. Después de 7 años y junto a un grupo pequeño de antropólogos, conversamos y decidimos intentar reactivar todo. Mi único interés y compartido por quienes trabajamos, era levantar el segundo congreso, dar continuidad a nuestra historia científica. Se debió hacer elecciones, por cierto, y fui elegida presidenta el año 1993, anunciando la única y no fácil tarea de trabajar por el segundo congreso. Se aceptó en asamblea organizar el congreso el año 1995. La Universidad Austral de Valdivia nos dio el patrocinio y fue la sede. Contamos con el inestimable apoyo de la directora del Departamento de Antropología, Priscila Délano, quien asumiría como la presidenta de la Comisión Organizadora y de Miguel Bahamondes, como Coordinador del Comité Ejecutivo. El segundo congreso tuvo el doble de participantes que el primero, fue muy exitoso y diverso. En el tiempo trascurrido había muchos estudios interesantes y temas emergentes como antropología poética, derecho y pluralismo, desarrollo, pueblos indígenas, género y antropología médica, entre otros. Terminamos con la publicación de las Actas en dos tomos con más de 400 páginas. Por esos años la historia escrita y publicada en papel, era importante. Terminado el Congreso, el colegio se reunió en asambleas, hasta que llegó el momento de nuevas elecciones y fui reelegida presidenta el año 1997. Como habíamos decidido que los congresos serían cada tres años, se acordó que el siguiente fuera en el año 1998. Solicitamos el auspicio en la Universidad Católica de Temuco y se organizó el congreso con el apoyo de la Facultad de Ciencias Sociales y Humanidades, al que pertenecía el departamento de antropología. Este congreso fue realmente magnífico y muy superior numéricamente a los otros, triplicando la cantidad de ponencias del primer congreso. Los resultados se publicaron en dos tomos con 600 páginas. Contamos con apoyo de Wenner Green Foundation lo que nos permitió traer destacados antropólogos extranjeros como Xavier Albó, Marc Augé, Bernardo Berdichewsky, Héctor Díaz Polanco y 
Larissa Lomnitz. Personalmente me interesaba mucho que la antropología de Chile se mirara en el contexto latinoamericano y conociéramos personalmente a algunos autores y autoras que leíamos. Fue un congreso con bastantes participantes de otros países, vinieron colegas de Holanda, Francia, Canadá, Estados Unidos, México, Nicaragua, Colombia, Ecuador, Perú, Bolivia, Argentina y Uruguay. Un éxito.

En resumen, respondiendo a la pregunta, mi interés desde el Colegio fue siempre el área científica, convencida que se debían crear espacios donde compartir el estado del conocimiento en Chile. Mi trabajo, por tanto, se circunscribió a esa tarea, levantar el Colegio nuevamente y luego organizar los encuentros en diferentes regiones del país, consciente, como ya lo he dicho, que estábamos construyendo la historia de la antropología y nuestra identidad como un cuerpo de profesionales. Luego de estos tres congresos, me alejé del Colegio y de alguna manera los congresos han seguido teniendo la regularidad. El último, el décimo, se realizó el año 2019.

Mi alejamiento esta vez obedeció a que había derivado hacia temas más específicos y poco trabajados en Chile y con ello, hacia otros desafíos, en torno a los derechos de los pueblos indígenas. El año 1993 había ingresado a la Comisión de Derecho Consuetudinario y Pluralismo Legal, sub comisión de la Unión Internacional de Ciencias Antropológicas y Etnológicas, UICAE, donde fui miembro del directorio junto a colegas de Alemania, Holanda y Canadá. Y en este contexto organizamos la Red de Antropología Jurídica. Un par de años después, el año 1996, fui elegida presidenta de la Asociación Latinoamericana de Antropología (ALA), en una reunión realizada en Varsovia en el contexto del
49ํㅡㄹ Congreso de Americanistas. ALA había sido fundada en 1990, por Guillermo Bonfill Batalla y no había realizado ningún congreso propio, solo nos reuníamos al alero de otros macro congresos como eran los de UICAE.

En este escenario, una de mis primeras acciones fue proponer un encuentro latinoamericano de antropólogos. Esta idea comenzó a concebirse el año 2003 en Santiago, en una reunión especial de ALA en el marco del $51^{\circ}$ Congreso Internacional de Americanistas: "Repensando las Américas en el umbral del siglo XXI", del que fui Secretaria General de la organización. Ese fue el congreso más grande de ciencias sociales que recuerdo en Chile, recibimos aproximadamente 4.000 personas de todo el mundo con connotados pensadores de las ciencias sociales y las humanidades. Bueno, y en aquella reunión de $A L A$, la propuesta de organizar un primer congreso fue recibida con mucho entusiasmo por la asamblea, entre ellos por los colegas argentinos. Recuerdo especialmente a Edgardo Garbulsky, quien propuso que fuera en Argentina. Fue así que el año 2005 se realizó el primer congreso de ALA en la ciudad de Rosario. Desde entonces se celebran con cierta periodicidad cada 3 o 4 años.

Por ese tiempo surgió otra organización, me refiero al Consejo Mundial de Asociaciones Antropológicas (WCAA) propuesto por Gustavo Lins Ribeiro el año 2004. En esa ocasión convocó a catorce presidentes de asociaciones de diferentes continentes, donde me correspondió representar a ALA. En reuniones posteriores abrimos un espacio para que también participara el Colegio de Antropólogos en WCAA. Yo no continué por mucho tiempo en esa red, pero entiendo que el colegio ha seguido participando. 


\section{AdS: ¿Y cómo ves al Colegio de Antropólo- gos en la actualidad?}

¿Cómo veo el Colegio? Lo cierto es que por el año 1985 teníamos un entusiasmo que inevitablemente era estimulado por el golpe que había dado la dictadura sobre las ciencias sociales, pero por otra parte veíamos la urgencia de organizarnos para asumir diferentes formas de protestas como vigilias, declaraciones, denuncias, tener presencia cuando colegas y estudiantes eran detenidos, en fin, sumarnos así al movimiento que se estaba gestando. Recordemos que tres años después terminó la dictadura mediante un plebiscito. Lo lamentable fue que con el retorno a la democracia el Colegio se desvaneció. Yo me alejé porque estaba en otras instancias de participación y organización donde, como señalé, tuve otros compromisos a nivel latinoamericano e internacional. Pero quisiera solo agregar que el Colegio podría haber tenido un rol pertinente, de carácter gremial, cuando el año 2006 una veintena de profesores y profesoras fueron exonerados del Departamento de Antropología de la Universidad de Chile, sin más razón que el hecho de que el ramo que impartían él o la docente no estaba contemplado en la nueva estructura que se había decidido en el plan de desarrollo. Se decía que se había utilizado un decreto que venía de los tiempos de Pinochet. Lo cierto es que el directorio del Colegio guardó silencio. Ese fue el golpe más duro que recibimos los colegiados, el hecho que aquel directorio, por razones que se desconocen, guardara silencio. Aparte de los congresos, no tengo información, he estado alejada y no he seguido sus derroteros.

\section{AdS: Cuéntanos un poco más acerca de la internacionalización de la antropología chilena, por ejemplo, a través de tu partici- pación en ALA o en RELAJU.}

Ya me he referido a mi participación en ALA. Respecto de la Red Latinoamericana de Antropología Jurídica, RELAJU, como he señalado, nace de una invitación que recibí para participar en un congreso en Accra, Ghana, el año 1995, con una ponencia sobre los conflictos por el agua en el norte de Chile. La presidenta de la Comisión de Falk Law and Legal Pluralism, Dra. Keebet Von Benda Beckmann, estuvo muy interesada por conocer acerca de los pueblos indígenas en América Latina. Propuse crear una red semejante a la que ella presidía y les pareció muy atractiva la idea. Así que comencé a trabajar llegando a Chile. La comisión tenía algunos nombres, principalmente de abogados, que estaban trabajando el tema de derechos indígenas. Por mi parte invité a María Teresa Sierra, a quién había conocido en un anterior congreso internacional, para coordinar un Simposio sobre el tema en el marco del congreso y conjuntamente organizar una reunión con los colegas latinoamericanos. Nos reunimos, discutimos sobre la posibilidad de crear una red, hubo acuerdo y nació así la Red de Antropología Jurídica RELAJU en julio de 1997. Aparte, María Teresa coordinó acciones para que la Revista América Indígena publicara los resultados del simposio. Al año siguiente me escribió la presidenta de la Comisión para que asistiera a una reunión intercongreso de UICAE (Unión Internacional de Ciencias Antropológicas y Etnológicas), el año 1998, donde me comunicaron que el directorio había tomado la decisión de realizar el siguiente congreso en América Latina, por lo que fui invitada especialmente para fundamentar las posibilidades 
de hacerlo. Contacté algunos colegas y hubo interés de Nicaragua y Colombia. México había sido sede de un Congreso de IUCAE el año 1993, con Lourdes Arizpe como presidenta. La asamblea optó por Chile, y me solicitaron que fuera la organizadora y presidenta del doceavo congreso de la comisión. Acepté y de regreso conversé con el decano Mario Orellana, para tener el patrocinio y realizarlo en nuestra Universidad. Lamentablemente ocurrieron hechos por los que debió dejar la decanatura el año 1999. En ese contexto, solicité conversar con el Departamento de Antropología, pero no estuvieron interesados, según me comunicó la directora Antonia Benavente. Entonces tomé la decisión de realizarlo con la Universidad de Tarapacá en Arica. Desde mi perspectiva, se abría una gran posibilidad para la internacionalización de la disciplina y obtuvimos suficientes fondos de la Cooperación Alemana. Trabajé junto a una destaca joven antropóloga, hoy la Dra. Gemma Rojas, con mucho convencimiento y fuerza, junto con otros profesores, pero especialmente alumnos y egresados de Derecho. El resultado fue un éxito, invitamos al decano de Ciencias Sociales, Fernando Durán, pero se excusó, también al decano de Derecho donde yo tenía jornada parcial, don Antonio Bascuñán, quien aceptó y dio una conferencia a nombre de la Universidad de Chile. Con los fondos pudimos invitar a colegas de África, Europa y de Latinoamérica. Llevamos traducción simultánea desde Santiago, fue un hito histórico. No solo fue el XII Congreso de la subcomisión de UICAE, sino nuestro segundo encuentro de RELAJU, y con una altísima cantidad de profesionales de Latinoamérica. Por lo mismo sugerí que lo consideramos nuestro $2^{\circ}$ Congreso. Sesionamos en una amplio y hermoso salón a orillas del mar, en Arica, fuimos al altiplano, tuvimos una fiesta bailable de cierre. Había mucha alegría por este primer encuentro latinoamericano-europeo. La mayoría de profesionales de la antropología, el derecho y disciplinas afines que asistieron, destacan en esta temática en sus países. Lo interesante es que sin otro compromiso que el de una red, ha permanecido en el tiempo y el próximo será nuevamente en México. Se crearon relaciones, lazos fraternales y de gran compromiso con los derechos de los pueblos indígenas. Con Gemma trabajamos día y noche para editar las Actas en solo tres meses en dos tomos que se pueden consultar en Internet. En Chile el tema indígena no era central en las carreras de antropología, eran solo cursos electivos. Ello explica no haber sacado más provecho de los maestros que nos visitaron.

\section{AdS: ¿A qué te refieres con que el tema indígena no era central en las carreras de antropología? Y ¿Por qué crees que eso sería así?}

Yo diría que todas las carreras tienen incorporado el tema indígena, sea desde la perspectiva de la arqueología y la etnohistoria, la etnografía, etnología, o con conceptos como inter o multiculturalidad. Desde mi punto de vista el tema indígena hoy no se puede entender solo desde la perspectiva de la etnografía y/o etnología. Sin duda los estudios, podríamos decir clásicos, propenden a elaborar etnografías que son valiosas como registro, pero desvinculadas de la realidad y de los procesos que han vivido y continúan enfrentando los pueblos indígenas. Los cursos que posteriormente se han impartido en las diversas carreras de antropología en el país, tengo certeza que sí han incorporado este tema como escenario de fondo, me refiero 
a la situación que viven los pueblos indígenas, cada vez más atropellados, maltratados, como resultado de políticas que se afanan por un integracionismo, gran motor para desarticular los pueblos y sus culturas. Pienso que se requiere profundizar en ello, reflexionar desde la antropología, teorizar avanzando hacia una antropología más comprometida que nos permita proponer soluciones.

Creo que hemos ido al ritmo de las modas, en la época del desarrollismo los estudios de comunidades indígenas abundaban, por ejemplo, o lo mismo para una antropología simbólica, excelentes análisis en torno a la cosmovisión de los pueblos. En fin, así han ido cambiando los intereses de la antropología. En mi opinión hoy el escenario nos exige otra perspectiva. Otros marcos teóricos y metodológicos latinoamericanos, de nuestra realidad.

AdS: ¿Cuál es el impacto que ha tenido la antropología jurídica en Chile? Pensando en el programa que diriges en la Universidad de Chile, en los trabajos de los colegas de Temuco y en la existencia de una coordinación nacional de RELAJU en Chile, ¿crees que se ha instalado y posicionado definitivamente la antropología jurídica en Chile? y si no, ¿qué falta para que eso ocurra?

¿Impacto? creo que no mucho. La antropología social que hemos aprendido, no ha prestado atención a normas, instituciones, sanciones y autoridades, por ejemplo, como fenómeno jurídico. Estudiamos la familia, las redes de parentesco $u$ otros fenómenos y lo que hacemos es extraerlas de una comunidad para llevarlas a un laboratorio teórico, y sacar una "foto" de una forma o figura organizacional en proceso de cambio. Y acá en mi opinión, viene lo interesante, ya que lo que cambia no es la estructura solamente, es su forma particular de organización jurídica, su derecho propio. El derecho, en cualquier sociedad, es el soporte del orden interno. Entonces, la fragmentación que hacemos de una realidad para el análisis teórico nos ha impedido observar el proceso por el cual la sociedad dominante ha avanzado en la desarticulación o desmembramiento de un pueblo. Las culturas son dinámicas, de acuerdo, y como el derecho propio es parte de la cultura, también cambia. Pero esta perspectiva es la que está ausente en la metodología antropológica. Cuando yo me inicié como antropóloga, en el altiplano estudiando las estrategias de subsistencia en las montañas o las formas de pastoreo o el uso y gestión del agua, hace muchos años, no tenía las herramientas metodológicas para observar en esos fenómenos cómo se desmembraba el territorio, cómo las políticas de integración destruían las prácticas culturales, cómo y porqué se les desconocía el derecho ancestral sobre los recursos naturales, sobre su territorio. Es por ello que, cuando fui testigo del desecamiento de humedales, apareció ante mis ojos antropológicos solo un nuevo fenómeno a investigar, sin cuestionar por qué ello ocurría sin haber ninguna sanción. Y serían los propios pueblos los que se levantaron y se defendieron. La antropología no tuvo mucho que decir, la mayoría de las investigaciones estaban en otras esferas. Entonces, esa perspectiva de la antropología, de volver la mirada hacía lo que estaba causando el derecho positivo de la sociedad dominante, es la mirada embrionaria de la antropología jurídica. En mi opinión esta nueva perspectiva integral es el campo de la antropología jurídica, como diría el Profesor Terradas, una antropología jurídica realista. No es fácil aprehender las dimensiones jurídicas 
separadas de las económicas o religiosas, y a la vez la relación con ellas. En esto hay que avanzar, porque hay otras formas de concebir la antropología jurídica. También quisiera agregar que se han desarrollado otros métodos para aproximarse a esa compleja realidad.

Lo cierto es que los acontecimientos que ocurrieron en la última década del siglo $\mathrm{XX}$ me llevaron hacia otro escenario. El cuerpo normativo internacional, en la Declaración de los Derechos Humanos sobre los Pueblos indígenas y el Convenio № 169 de OIT, reconocen derechos de los pueblos indígenas, insospechados hasta entonces, como el derecho a su territorio, a los recursos naturales, al derecho propio, a la autonomía y muchos otros derechos hoy reconocidos como "colectivos", no individuales, que era el concepto que surge en derecho desde mediados del siglo pasado con la Declaración de los Derechos Humanos. En este nuevo escenario había mucho trabajo por hacer. En primer lugar, que los especialistas del derecho y los propios pueblos indígenas conocieran la nueva normativa. Por ello, estando en la Facultad de Derecho de la Universidad de Chile, impartiendo la cátedra Derechos Indígenas, se creó el Programa de Antropología Jurídica, plataforma para iniciar una serie de actividades, como fue el Congreso Internacional sobre Derecho Consuetudinario y Pluralismo Jurídico, en la ciudad de Arica. Llegaron muchos jóvenes abogados y abogadas que hoy son reconocidos profesionales y continuaron en esa línea del Congreso, ese ha sido un gran resultado. Después he promovido reuniones en Chile con especialistas internacionales, Cursos de Especialización y Diplomados. Siempre en coordinación con colegas de la Red Latinoamericana de Antropología Jurídica (RELAJU). Fue así como el año 2018 se convocó a participar en el X Congreso de RELAJU en Chile, en las ciudades de Santiago y Temuco. Con ello se esperaba fortalecer una red de Antropología Jurídica en el país, como resultado de ese encuentro internacional y organizar y crear algún tipo de asociación que reuniera a los y las especialistas, pero no hubo mayor interés. Curiosamente son mayoritariamente los abogados quienes se han interesado en cruzar la frontera hacia la antropología jurídica. Debo destacar, sin embargo, que el escenario de hoy muestra focos muy interesantes de trabajos en otras Universidades como la Universidad Católica de Temuco, la propia Universidad Academia de Humanismo Cristiano y otras más tanto en el norte como en el sur del país. Pero como ocurre casi siempre, en esta etapa constructiva, estamos algo dispersos. Sería oportuno promover encuentros nacionales, seguro veríamos interesantes aportes y avances y un gran compromiso de profesionales de la antropología y el derecho para trabajar en forma conjunta. Eso faltaría, reunirnos en Chile, plantear nuestras inquietudes teóricas, porque denuncias tenemos bastante.

\section{AdS: Y a propósito de tus trabajos en el norte ¿Qué lugar ocupan esas comunidades y en general las comunidades campesinas en tu perspectiva de la antropología?}

Ocupan el primer lugar. Pero aclaro que no puedo decir que eso fue así en los inicios de mi trabajo. En el origen está mi opción por conocer la extrema pobreza urbana en nuestro país, como les he comentado, en los botaderos de basura. Por otro lado, en los años setenta, había un gran interés por sobre lo que se llamaba "El hombre andino" o "la Cultura andina" y se sumaba a ello el surgimiento de la "música andina que se extendía por todo lo que había sido el imperio inca -aunque eso sería cuestio- 
nado por la dictadura-, la valoración de la historia andina, observábamos un fértil movimiento intelectual, muy atractivo para quienes egresábamos. De hecho, el año 1973 se realizó en Chile el Primer Congreso del Hombre Andino, en las ciudades Arica, lquique y Antofagasta, fue un hito importante a pocos meses del golpe militar. Precisamente yo no fui porque se rumoraba que algo grave podía ocurrir, ello porque en junio se había producido una sublevación militar que fue sofocada por el general Prats y que se conoce como el Tancazo. Después, en 1977 fuimos varios egresados al Tercer Congreso del Hombre y la Cultura Andina, en Lima. Fue espectacular, con grandes maestros como expositores, recuerdo brillantes conferencias por ejemplo de John Murra, de Luis Lumbreras. Era un tiempo de gran efervescencia política en Perú y nos sorprendió el nivel de conocimientos teóricos del estudiantado peruano y su compromiso con el mundo andino. Hubo por esos tiempos excelentes profesionales de la antropología. Por ello, cuando tuve mi primer proyecto que me llevó al altiplano, comencé a buscar a aquellos maestros, como John Murra, José Matos Mar, Fernando Fuenzalida, Luis Millones, Enrique Mayer, Jorge Flores Ochoa, fotocopiando cada registro que encontraba.

El curso que tomaría mi vida profesional deriva de una invitación a participar en un proyecto del Programa "El hombre y la biósfera" de UNESCO en el altiplano de la ciudad de Arica, en el extremo norte del país, el año 1979, en un equipo de la Facultad de Medicina conformado por especialistas en adaptación a la altura. Posteriormente, el año 1982, recibí otra invitación para integrar un equipo interdisciplinario de investigación en la IV Región de Coquimbo, en la zona de comunidades campesinas, conocidas como Comunidades Agríco- las, en el marco de otro programa de UNESCO, "El hombre y los ecosistemas de pastoreo", también interdisciplinario, con ingenieros agrónomos y veterinarios. Estas dos importantes investigaciones multidisciplinarias marcaron la ruta que seguiría: el mundo rural campesino de zonas semiáridas y los pueblos indígenas de las montañas del norte chileno. El enfoque era fundamentalmente bajo una perspectiva de la antropología económica ya que me interesaban las estrategias de subsistencia en zonas de limitados recursos. En la región de Coquimbo no había estudios antropológicos, no obstante los escritos de Ximena Aranda, geógrafa, fueron guía para algunos temas de mi investigación. En el área había comenzado a desarrollarse una línea en estudios andinos, que fue cortada por las consecuencias del golpe militar. Destaco autores que hicieron notables aportes como Tristán Platt, antropólogo inglés que escribió una monografía sobre las comunidades en la cabecera del rio Azapa. Fue un texto que influyó en mi trabajo. También estaban Gabriel Martínez y Juan Van Kessel. Por cierto, la arqueología tenía un gran desarrollo.

\section{AdS: Por esa época comenzaron tus traba- jos en torno al agua, un tema que iniciaste muy tempranamente y que hoy es un tema fundamental...}

Como ya les he comentado, mi interés por el agua nace cuando se privatiza este recurso, se lanza al mercado. Si bien es cierto que la lucha por el agua entre las poblaciones andinas y los intereses urbanos arrancan desde la colonia, a partir de 1981 se aceleró. Las empresas mineras, principalmente, comienzan a inscribir derechos de aguas generando un severo daño en los humedales de altura, base del pastoreo 
altoandino, el que a su vez ha sido clave en las estrategias de sobrevivencia, porque las condiciones climáticas restringen la agricultura sobre los 4.000 metros. En ese tiempo tuve varios proyectos de investigación que trataban de alguna forma el recurso hídrico. En 1988 participé en un proyecto binacional sobre sistemas acuáticos altoandinos en un grupo interdisciplinario entre Chile y Argentina, con el auspicio de UNESCO y OEA. Posteriormente tuve la posibilidad de asumir otro estudio sobre un tema que desconocía, cultura hídrica, solicitado por otro Programa de UNESCO el año 1992. Conformé un grupo interdisciplinario y nos fuimos, en una aventura, por tierra hasta Socoroma, poblado andino del extremo norte a 3.000 metros, aproximadamente. El tema era interesante, seguimos a Felipe Bates en su definición de cultura, para poder integrar la gestión del agua, aspectos económicos y simbólicos. Fue un trabajo pionero en el norte, los resultados los publicó UNESCO. Pero fue en 1992 con el estudio de humedales que elaboramos para la Dirección General de Aguas, en que se fortaleció aún más esta línea y demostramos que vendría la lucha por el agua. El estudio comprendía todo el extremo norte del país, lo que eran la I Región de Arica y la II Región de Antofagasta sobre los 3.000 metros, donde identificamos algo más de 400 humedales y también mostramos la enorme cantidad de agua que había sido solicitada y otra cantidad mayor de solicitudes de derechos de agua superficiales y subterráneas. La mayor satisfacción fue el hecho de que se cambiara, como les comenté, un artículo del Código para proteger estas fuentes de agua. Esta investigación fue clave para otros estudios, como el uso de los humedales en el pastoreo o los sistemas de riego en zonas agrícolas más bajas, precordilleranas. Todo esto en un entramado de publicaciones en congresos, participación en redes sobre el tema, etc.

Ha sido en Perú donde he encontrado una abundante bibliografía, ha habido una enorme cantidad de estudios sobre la gestión del agua desde los tiempos preincaicos, de las redes hidráulicas, el manejo del agua en la andenería, el agua y poder político.

\section{AdS: Pasando a otro tema, ¿Cuál crees que es el aporte de la antropología chilena al ámbito latinoamericano y mundial?}

No es fácil contestar esta vastísima pregunta, pero me atrevo a decir que el desarrollo de una antropología post dictadura, después de haber sido destrozada, desarticulada, debió iniciar un proceso de búsqueda de horizontes teóricos, muchas veces a contrapelo de una formación académica que no siempre responde a las expectativas o a las necesidades de la disciplina. Cuando revisamos las actas de los congresos es interesante ver cómo aparecen y desaparecen algunos temas, cual moda. En parte obedecería al contexto en el que se puede investigar, una tesis, un proyecto Fondecyt, por ejemplo. Quienes tienen el privilegio de contar con financiamiento pueden proyectar sus estudios. Son casos privilegiados de grupos que han consolidado su trabajo en redes prácticamente cerradas. Por lo tanto, la voz que se escucha es de quienes han tenido ese privilegio. La investigación en Chile, sin lugar a dudas, es un gravísimo problema. En este contexto, pienso en algo que se ha reiterado bastante, el verdadero reto es el fomento de la investigación de la mano con el fomento a la teorización, respondiendo a nuestro contexto latinoamericano. EI aprendizaje de esta teorización debe iniciarse en el aula cuidando que, como señaló Esteban 
Krotz, la teoría no se reduzca a una "genealogía de autores". Desde esta argumentación, pienso que lo que ha podido exportar la mayoría de los antropólogos y antropólogas es un abundante y rico conocimiento empírico, muchas veces materia prima para ejercicios teóricos de las antropologías del norte. Por otro lado, no puedo dejar de mencionar que hay notables aportes individuales, producto de esfuerzos e inquietudes que han dado a conocer parte del quehacer de la antropología en Chile. Nuestro aporte, no menor, a la antropología latinoamericana se circunscribe a este escenario.

\section{AdS: ¿Cómo ves el presente de la antro- pología chilena y su relación con algunas de las configuraciones socioculturales contemporáneas en el país, por ejemplo, en relación al género, feminismo, etnicidad o migración o al mismo estallido social de octubre?}

De partida, me parecería muy interesante y valioso si la antropología pudiera institucionalizar el estudio, análisis y la teorización de estos fenómenos. Actualmente, hay muchísimos temas que deberían tomar cuerpo sólido de la mano con el contexto político-económico que vive el país, bajo los efectos de la globalización del capitalismo. Otros temas como el estallido social, la violencia policial o violencia permitida, en las calles o con los pueblos indígenas, la mutilación de jóvenes, producto de las protestas. También está, ad portas y como resultado de la pandemia, la develación de la pobreza extrema que había en este país. Con esta base de estudios, más que dar cuenta con exhaustivos relatos, la antropología debería propender a generar un modelo de cambio de una sociedad que es resultado del fracaso del modelo neoliberal. Ha sido una política desde la instalación de la dictadura, el ejercicio del control de los medios de comunicación por parte de las elites dominantes, sería interesante explorar en una antropología de los medios de comunicación.

\section{AdS: Ya para finalizar, ¿Cómo proyectas el desarrollo de la antropología chilena?}

Puedo dar mi opinión desde un área muy especializada de la Antropología, me refiero a mi opción por el campo de la antropología y el derecho, específicamente al derecho de los pueblos indígenas. Observo un creciente interés, tal vez muy de la mano con una opción política, por una antropología en el contexto de los derechos humanos, por el derecho a la diversidad, a la no discriminación, al derecho de las mujeres, etc. $Y$ en este nuevo campo, al menos en Chile, la antropología tiene muchísimo que aportar.

Pero intentando una proyección más allá de mi opción. Yo diría que hay algunos frenos; por un lado, la formación que se recibe en el proceso de enseñanza académica que no es decisoria en el futuro del egresado. El camino dependerá de las posibilidades laborales, es decir de la fuente de trabajo que encuentre, y en esta fuente hay riesgos de volvernos partes funcionales de un sistema que no es nuestra elección. Por otra parte, la educación del aula se ha aferrado a las antropologías del norte, de otras realidades culturales, económicas y de contextos históricos diferentes. Nos esmeramos por forzar las teorías aprendidas para explicar realidades distintas, como es la de nuestra América latina. Esta mirada crítica es relativa. Por cierto, no adhiero de manera absoluta a esta portura, pues hay otra perspectiva que nos debe alentar, es la de una importante producción de conocimiento donde cada generación 
ha sido estimulada por momentos históricos; como también ha habido países que han desarrollado más un pensamiento crítico, como es el caso de México. Más bien tiendo a pensar que nuestra antropología se está abriendo a un pensamiento crítico estimulado por la mirada crítica a nuestro propio país, a la producción de un nuevo conocimiento y a la urgencia de estimular la producción teórica, desde las aulas.
Me pregunto si en este complejo contexto que vive la sociedad latinoamericana con realidades compartidas, de antropologías periféricas, si no sería éste el momento de crear un Sociedad Chilena de Antropología, que active el pensamiento disciplinar y tenga su propia revista, en una relación complementaria a las actividades académicas que ha venido realizando el Colegio de Antropólogos. 